\title{
Effects of Exercise on Vascular Function, Structure, and Health in Humans
}

\author{
Daniel J. Green ${ }^{1,2,3}$ and Kurt J. Smith ${ }^{2}$ \\ ${ }^{1}$ Research Institute for Sport and Exercise Sciences, Liverpool John Moores University, Liverpool L33AF, United \\ Kingdom \\ ${ }^{2}$ School of Human Sciences, The University of Western Australia, Crawley 6009, Australia \\ ${ }^{3}$ Principal Research Fellow, National Health and Medical Research Council of Australia, Canberra 2601, \\ Australia \\ Correspondence: danny.green@uwa.edu.au
}

\begin{abstract}
Physical activity has profound impacts on the vasculature in humans. Acute exercise induces immediate changes in artery function, whereas repeated episodic bouts of exercise induce chronic functional adaptation and, ultimately, structural arterial remodeling. The nature of these changes in function and structure are dependent on the characteristics of the training load and may be modulated by other factors such as exercise-induced inflammation and oxidative stress. The clinical implications of these physiological adaptations are profound. Exercise impacts on the development of atherosclerosis and on the incidence of primary and secondary cardiovascular events, including myocardial infarction and stroke. Exercise also plays a role in the amelioration of other chronic diseases that possess a vascular etiology, including diabetes and dementia. The mechanisms responsible for these effects of exercise on the vasculature are both primary and secondary in nature, in that the benefits conferred by changes in cardiovascular risk factors such as lipid profiles and blood pressure occur in concert with direct effects of arterial shear stress and mechanotransduction. From an evolutionary perspective, exercise is an essential stimulus for the maintenance of vascular health: exercise is vascular medicine.
\end{abstract}

\section{RELEVANCE OF THE VASCULAR IMPACTS OF EXERCISE}

$\mathrm{B}^{\text {eing }}$ physically active decreases the risk of Bacute myocardial infarction and ischemic stroke, two leading global causes of death, morbidity, and health care cost (Paffenbarger et al. 1986; Manson et al. 1999). Despite research into the clinical benefits of exercise being a "blind spot," with clear evidence of a bias toward the assessment of drug interventions (Naci and
Ioannidis 2013), a recent comparative analysis suggested that the impact of exercise on mortality approximates that associated with the use of cardiovascular (CV) medications (Naci and Ioannidis 2013). The exception was stroke rehabilitation, in which the exercise benefit was superior.

In the context of secondary prevention, studies performed in the contemporary era of clinical management indicate that exercisebased cardiac rehabilitation reduces hospitalization and CV mortality and improves health-re-

Editors: Juleen R. Zierath, Michael J. Joyner, and John A. Hawley

Additional Perspectives on The Biology of Exercise available at www.perspectivesinmedicine.org

Copyright (C) 2018 Cold Spring Harbor Laboratory Press; all rights reserved; doi: 10.1101/cshperspect.a029819

Cite this article as Cold Spring Harb Perspect Med 2018;8:a029819 
lated quality of life (Anderson et al. 2016). The risk reduction did not differ between programs involving exercise alone, versus "comprehensive" cardiac rehabilitation (i.e., rehab involving exercise plus lifestyle advice, dietary interventions, etc.), suggesting that exercise is a key rehabilitative component. However, exercisebased cardiac rehabilitation may not reduce the risk of repeat myocardial infarction or the need for revascularization (Anderson et al. 2016), raising questions regarding the mechanisms responsible for the beneficial impacts of exercise.

Ultimately, the clinical role of exercise as a therapy in the treatment of CV diseases revolves around the question of whether it produces benefits that add to those associated with contemporary prevention and management strategies. For example, is it worth the trouble and expense of adding exercise-based therapy to drug and revascularization approaches (Hambrecht et al. 2004)? From a physiological perspective, some insight into this question can be gained from considering the direct and indirect effects of exercise on arterial function and structure in humans.

\section{Exercise Effects on the Vasculature: Primary and Secondary Benefits}

Due to the predominance of the risk-factor paradigm in prevention of CV diseases, historical emphasis was placed on the effects of exercise interventions on blood pressure, lipids, insulin resistance, smoking cessation, and obesity (Thompson et al. 2003). That is, the focus was predominantly on "surrogate" endpoints rather than directly on the end organs, the arteries per se. These indirect, or "secondary," benefits of exercise are real and important, but generally not as great as the impact of drug therapies for each individual CV risk factor. Nonetheless, exercise modifies multiple risk factors and in this sense it is a "polypill," capable of addressing the consequences of adverse behaviors that reinforce a mismatch between our genetic background and modern Western "lifestyles" (Booth et al. 2002). Indeed, the impacts of exercise on $\mathrm{CV}$ risk reduction exceed those directly attrib- utable to effects on traditional $\mathrm{CV}$ risk factors (Mora et al. 2007). A "risk-factor gap" therefore exists in accounting for the beneficial impacts of exercise in humans (Green et al. 2008).

Several mechanistic explanations exist for the missing risk reduction, including impacts on novel risk factors and those that are not easily quantified, such as autonomic nervous system function (Joyner and Green 2009). Another prominent possibility is that exercise has direct, or "primary," mechanical effects on the arteries by virtue of repetitive exposure to increases in blood pressure, blood flow, and arterial shear stress that occur during each exercise bout (Fig. 1) (Green et al. 2017). Exercise induces adaptations in the vessel wall that are antiatherogenic (Green et al. 2008; Joyner and Green 2009), including effects on endothelial and smooth muscle cell function, along with structural remodeling of the arteries. This brief review will focus on the impact of exercise and physical activity on adaptations in the function and structure of arteries. Although much valuable insight into mechanisms has been derived from animal studies of vascular adaptation (see, especially, Jasperse and Laughlin 2006), this review focuses on human techniques and experimental data to emphasize the translational relevance to $\mathrm{CV}$ diseases.

\section{EARLY STUDIES OF THE IMPACT OF EXERCISE TRAINING ON THE VASCULATURE: THE CONTRIBUTIONS OF PLETHYSMOGRAPHY}

Prior to the development of imaging approaches that assess large artery diameter and Doppler measures of blood flow velocity, the most common method used to assess vascular function and structure in humans was plethysmography (Joyner et al. 2001). The principle of this technique, based on Harvey's proofs of the circulation, is that inflation of a blood pressure cuff on a limb (e.g., upper arm or thigh) to a modest pressure $(40-50 \mathrm{mmHg}$ ) collapses the collecting veins and induces limb swelling, which can be quantified as a volume change. Older water-displacement methods were superseded by circumferential attachment of silastic bands 
Effects of Exercise on Vascular Function, Structure, and Health

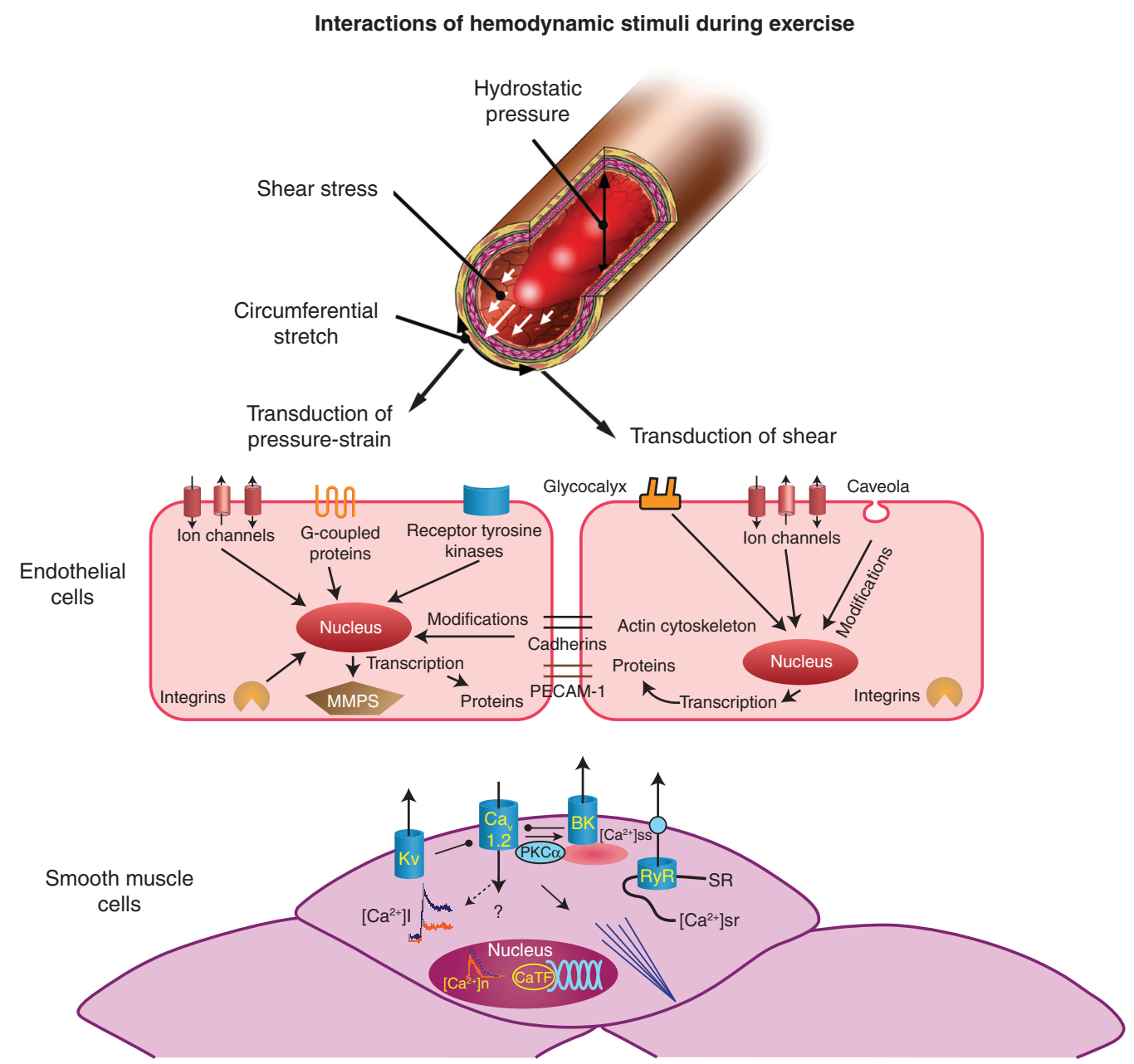

Figure 1. Hemodynamic stimuli and their effects on vascular function and adaptation. (From Green et al. 2017; adapted, with permission.)

filled with mercury or gallium/indium, through which an electric current was transmitted (Whitney 1953). The rate of stretching of the bands during cuff inflation modifies impedance, from which the rate of change in diameter, cross-sectional area, and volume of the limb can be mathematically derived. In the era of magnetic resonance, computed tomography, and high-resolution ultrasound, this technique may seem indirect, but important observations regarding the impacts of exercise on the vasculature were made throughout the 20th century using strain-gauge methodology (Joyner et al. 2001).
Impacts of Exercise on Resistance and Conduit Artery Remodeling: Arterial Lumenal Expansion

Early plethysmographic studies focused on exercise training effects on resistance vessel adaptation (Sinoway et al. 1987; Snell et al. 1987; Silber et al. 1991; Green et al. 1994). One approach was to induce maximal limb dilation using prolonged cuff occlusion or a combination of ischemia and exercise. Given that such stimuli induce peak reactive hyperemic blood flow responses (Folkow 1978; Naylor et al. 2005), increases with training infer remodeling 
of the resistance vessels. Such remodeling might include exercise-induced angiogenic growth in the number of capillaries and small arterioles (Andersen and Henriksson 1977; Brown 2003), but more likely reflects outward circumferential remodeling of larger arterioles and feed arteries, which are principally responsible for the control of vascular resistance (Sinoway et al. 1987; Snell et al. 1987; Silber et al. 1991; Segal 1992; Green et al. 1994). These larger arterioles, which represent the primary sites of resistance to large increases in flow, do not increase in number with training, rather their lumenal dimensions expand. Studies that compared exercise-trained versus - untrained limbs, within-subjects (e.g., tennis, squash players) (Sinoway et al. 1986; Green et al. 1996; Rowley et al. 2011), as well as studies that followed individuals before and after handgrip or leg exercise programs (Sinoway et al. 1987; Snell et al. 1987; Green et al. 1994), typically showed increases in peak reactive hyperemic blood flows. These data provide the foundation for the now well-established concept that exercise training is associated with outward structural remodeling of resistance arterioles and feed arteries in humans (Green et al. 2004).

Further support for the idea that exercise induces arterial enlargement emerged from studies performed later, using imaging approaches. Such studies showed that conduit arteries increase in size as a result of exercise training (Dinenno et al. 2001; Spence et al. 2013). Other studies showed that prolonged inactivity is associated with the corollary, inward remodeling (Green et al. 1997; Huonker et al. 2003; Thijssen et al. 2012b). The observation that preferred limb vessels are larger than those in nonpreferred limbs, for example, in racquet sportsmen (Rowley et al. 2011, 2012), inferred that a localized mechanism such as repetitive increases in blood flow and shear stress might contribute as a stimulus to remodeling. This does not preclude the possibility of generalized vascular remodeling, for example, in the upper limbs as a result of predominantly lower limb training (Birk et al. 2012): lower limb exercise alters blood flows and shear stress in inactive vessel beds such as the upper limbs (Green et al. 2002a,b), although qualitative and quantitative differences exist between localized and systemic effects of exercise in terms of arterial hemodynamics (Green et al. 2005). The volume of exercise required to induce systemic adaptation may therefore be greater than that required to induce localized changes in vessels feeding the working musculature.

The importance of using a stimulus to reveal structural adaptation in these studies was emphasized by the finding that basal or resting blood flows and arterial diameters are rarely modified after training, despite consistent evidence that peak reactive hyperemic measures of arterial capacity are enhanced. This finding reinforces the fact that there are a multitude of factors that control arterial tone and it may be that adaptations in arterial "capacity" are only apparent in the absence of such competing influence: building a bigger engine does not necessarily mean that it will idle at a higher rate (Green et al. 2004; Sugawara et al. 2007).

The studies described above, which directly addressed the question of structural enlargement of conduit and resistance arteries in response to exercise training, reinforced much earlier case reports or observational evidence that regular exercise enhanced the size of coronary vessels (Currens and White 1961; Mann et al. 1964). It is also important to emphasize that the in vivo human experiments presented above, which relate to the impacts of exercise on the vasculature, are strongly supported by animal data. Classic studies have established that repeated increases in blood flow and shear stress induce remodeling of arteries and that such responses are dependent on the presence of an intact and functional endothelial layer (see below) (Langille and O’Donnell 1986; Tronc et al. 1996; Rudic et al. 1998; Tuttle et al. 2001).

\section{Impacts of Exercise on Resistance and Conduit Artery Remodeling: Arterial Wall Thickness}

In the 1950s, Folkow applied the principle that reduction in peak reactive hyperemic blood flow responses, for example, in patients with "essential” hypertension, reflects global increases in 
the wall thickness of resistance arterioles in humans (Folkow et al. 1958). He concluded that such increases and concomitant increases in wall-to-lumen ratios contribute to the raised peripheral resistance that characterizes primary hypertension (Folkow 1978). The well-established increases in peak reactive hyperemia that result from training (outlined above) may, at least in part, be caused by resetting of the wall:lumen ratio. While it is not currently possible to image smaller resistance vessels in humans to confirm Folkow's important ideas regarding the role for wall thickness in pressure regulation, or the impacts of exercise, evolving ultra-high-resolution imaging techniques hold some promise that this will be possible in the future (Carter et al. 2016).

In larger conduit arteries, it is possible to assess wall thickness, although such measures lie close to the limit of current imaging capability. High-resolution ultrasound has been widely adopted to assess carotid artery wall thickness, and this has been used as a surrogate for atherosclerosis and is related to CV endpoints. Studies assessing wall thickness in large arteries in response to exercise training have recently emerged and several suggest that changes in the wall:lumen ratio occur with training (Maiorana et al. 2011; Thijssen et al. 2012a; Spence et al. 2013). This may be a consequence of structural remodeling of the wall but it is also apparent that acute changes in smooth muscle contractile state are associated with changes in wall thickness in vivo (Thijssen et al. 2011b), so the effects of training on arterial function may also contribute to the apparent change in wall thickness. Further studies and improved imaging techniques are needed to address the extent to which exercise training remodels large and small artery wall thickness in humans.

\section{STUDIES OF EXERCISE TRAINING IMPACTS ON ARTERY FUNCTION}

Several developments converged in the late 20th century to focus attention on changes in artery function as a result of exercise in humans. First, the studies described above, which established that changes in vasodilator capacity occur following training, raised questions around the mechanisms responsible. At the same time, discovery of the obligatory role of the endothelium as a regulator of vascular tone and blood pressure, by virtue of the production of paracrine hormones such as prostaglandins and nitric oxide (NO), raised interest around the possible impacts of exercise on endothelial regulation (Moncada et al. 1976; Furchgott and Zawadzki 1980). Finally, it was established that change in blood flow, and consequential endothelial shear stress, was a potent physiological stimulus to the production of paracrine hormones from the endothelium and that the endothelium regulated local arterial diameter and shear stress in response to mechanotransduction (Pohl et al. 1986; Rubanyi et al. 1986).

The hypothesis that exercise training might modify endothelial function in humans was first addressed in 1994 (Green et al. 1994). This was followed by another study comparing the preferred and nonpreferred limbs of elite racquet sportsmen (Green et al. 1996). These studies combined forearm blood flow (FBF) measures derived from plethysmography with intrabrachial infusions of NO agonists and antagonists. Studies adopting this approach multiplied through the subsequent decade (Fig. 2) (Green et al. 2004), particularly in clinical populations in whom it became apparent that improving endothelial function was a clinical imperative. We have previously summarized this literature (Green et al. 2004; Thijssen et al. 2010), the major outcomes being: (1) exercise training consistently induces improvements in both conduit and resistance artery NO-mediated function, (2) improvements were most often isolated to the endothelial cells, rather than the underlying smooth muscle, (3) improvements in function were generally more apparent in subjects with impaired endothelial function a priori, and (4) improvements in function were sometimes, but not always, accompanied by evidence for structural vascular enlargement.

Notable among these studies were findings from Hambrecht et al. (2000), who reported in vivo coronary vascular functional adaptations in response to training. They also cleverly com- 
D.J. Green and K.J. Smith
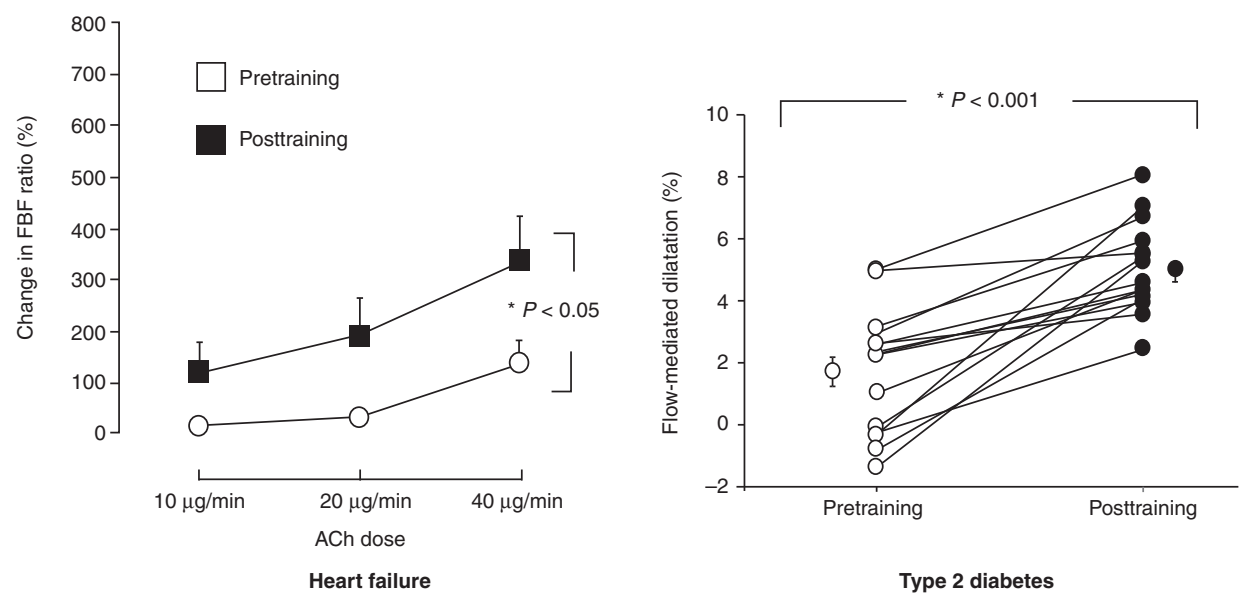

Figure 2. Some examples of studies investigating the impacts of exercise training in humans, including studies using plethysmography and intrabrachial infusion of agonists and antagonists of endothelial pathways (Maiorana et al. 2000) and conduit artery functional assessment using flow-mediated dilation (FMD) (Maiorana et al. 2001). FBF, Forearm blood flow.

bined in vitro, in situ, and in vivo approaches in a bench-to-bedside study of the impacts of training on adaptation of the internal mammary artery (Fig. 3) (Hambrecht et al. 2003). This study implicated shear stress-mediated changes in NO synthase levels in endothelial cells as the mechanism responsible for enhanced endothelial function in response to training, in keeping with animal studies that also convincingly established a role for repeated episodic increases in shear (Langille and O'Donnell 1986; Tronc et al. 1996; Rudic et al. 1998; Tuttle et al. 2001). Since endothelial cells and the production of $\mathrm{NO}$ are key factors in the prevention of atherosclerosis, these studies were directly clinically relevant to the impact of exercise on conduit artery health in vivo. The important studies of Hambrecht remain exemplars, but they did not directly address the hypothesis that shear stress was the mechanism responsible for exerciseinduced changes in vascular function.

Subsequent technical and software development facilitated studies pertaining to the impact of distinct forms of exercise on arterial blood flow and shear stress in different vascular beds in vivo. High-resolution duplex ultrasonography, combined with the insight that increases in blood flow (and hence shear stress) increased arterial diameter (Anderson and Mark 1989;
Sinoway et al. 1989), led to the introduction of the flow-mediated dilation (FMD) approach for noninvasive assessment of conduit artery function in humans (Celermajer et al. 1992). Subsequent blockade studies established that FMD was largely endothelium-dependent and NO-mediated (Green et al. 2011), making the FMD approach, when correctly applied (Thijssen et al. 2011a), a useful research tool for assessment of conduit artery function in humans. Later development, whereby the diameter measures were combined with real-time simultaneous assessment of blood velocity, and hence blood flow (Green et al. 2002b), further enhanced the utility of this approach as conduit artery function could be gleaned from the directly visualized diameter changes, whereas changes in large artery (e.g., brachial, femoral) blood flow could be used to replace the less direct assessments of limb blood flow formally derived using plethysmography (see above). Hence, a single technique could provide information reading conduit artery function (e.g., FMD) and structure (peak conduit vasodilator responses) and resistance vessel structure (peak blood flow responses) (Naylor et al. 2005). More recent developments enabled the real-time and continuous assessment of conduit artery shear rate across the cardiac cycle, allowing both the 


\section{A}
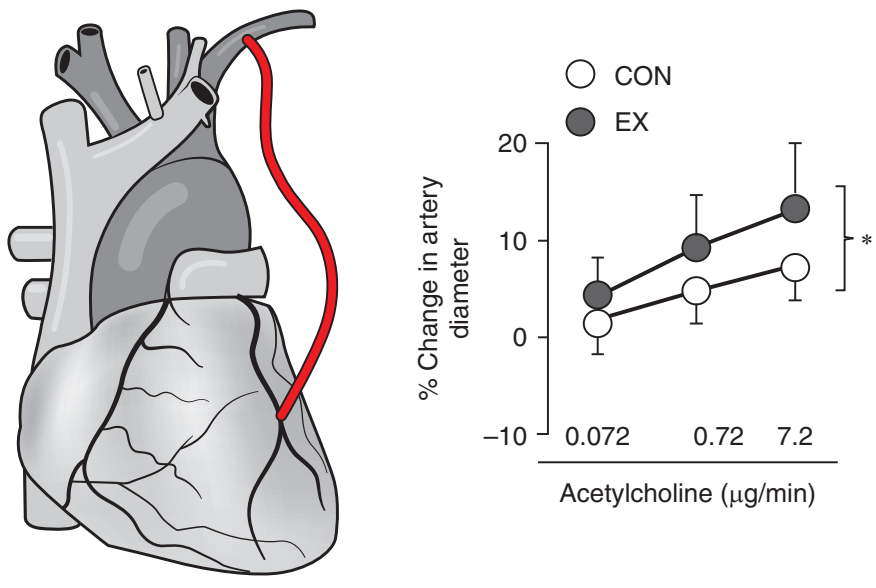

B
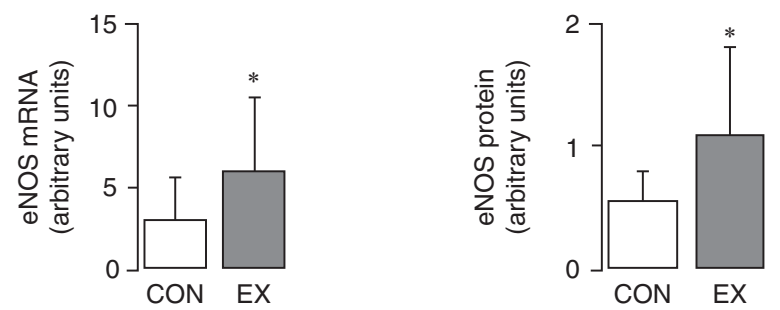

Figure 3. Summary of a bench-to-bedside study incorporating in vivo $(A)$, in situ, and in vitro $(B)$ evidence for shear mediated adaptation in endothelial function in humans as a result of exercise training (Hambrecht et al. 2003). (From Green et al. 2017; adapted, with permission.) Studies were performed on the internal mammary artery. eNOS, Endothelial nitric oxide synthase.

stimulus for diameter change and the magnitude of diameter response to be simultaneously recorded (see Fig. 4) (Green et al. 2002b; Thijssen et al. 2011a).

The literature relating changes in hemodynamic stimuli and arterial adaptation was recently summarized in Physiological Review (Green et al. 2017). In brief, it is clear that exercise is a stimulus that modifies transmural pressure, cyclic circumferential strain on the artery wall, along with endothelial shear stress (Fig. 1). These are stimuli that are detected in the artery wall. Distinct forms of exercise (e.g., mode, intensity) can induce different patterns of arterial pressure, blood flow, and shear stress that are, in turn, associated with distinct forms of vascular adaptation. The nature of adaptation in different vascular territories, for example, those involving skeletal muscle activation versus those feeding inactive muscle, is also con- sequentially influenced by the specific pattern of flow and pressure change induced by exercise.

Some of the studies performed in humans establishing the role of shear stress in mediating exercise training-induced vascular adaptation involved direct manipulation of shear during repeat bouts of exercise (Fig. 5). This was achieved using partial inflation of a blood pressure cuff on one arm, such that blood flow and shear through that cuffed limb was "clamped" at near resting levels, whereas blood flow through a contralateral exercising limb was allowed to increase (Tinken et al. 2010a). These studies showed that conduit artery endothelial function was enhanced in the exercised limb in which blood flow substantially increased, whereas no such functional adaptation was apparent in the opposing limb, although it had been exercised at identical levels. Such studies, involving bilateral handgrip exercise performed 

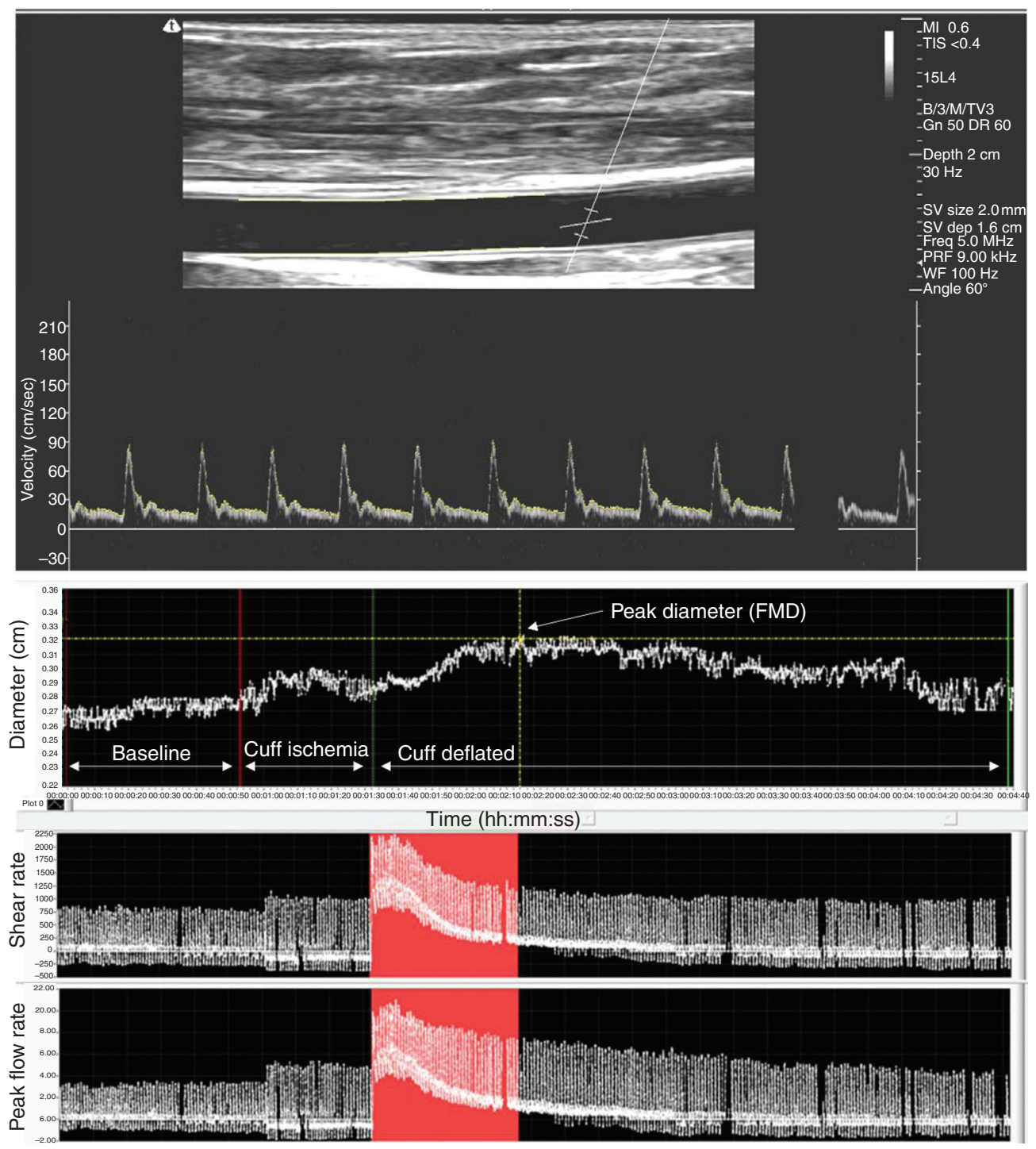

Figure 4. High-resolution duplex ultrasound image of a brachial artery. Software enables continuous edgedetection and wall tracking of the B mode image, whereas the velocity envelope is also automatically recorded (live feedback of tracking is seen as the yellow tracing). Simultaneous velocity and diameter measures are recoded and saved at $\sim 30 \mathrm{~Hz}$, and output generated (left). Output includes continuous diameter tracing, blood flow, and shear rate (other variables are also available including velocity, pressure, etc.). These tracings illustrate a typical flow-mediated dilation (FMD) response as a result of $5 \mathrm{~min}$ of limb ischemia. Note the large blood flow/shear rate response to cuff deflation and the biphasic (increase and then decrease) response in diameter. FMD is endothelium-dependent and largely nitric oxide (NO)-mediated (Green et al. 2011) and provides a surrogate index of conduit artery function and health in humans (Thijssen et al. 2011a). Longer periods of cuff ischemia, or cuff ischemia whereas performing exercise (e.g., ischemic handgrip), result in maximal diameter and blood flow responses (Naylor et al. 2005) that provide valuable information regarding structural changes (e.g., lumenal enlargement in response to exercise training) in resistance arteries downstream from the conduit arteries. See text for further explanation. 
Effects of Exercise on Vascular Function, Structure, and Health

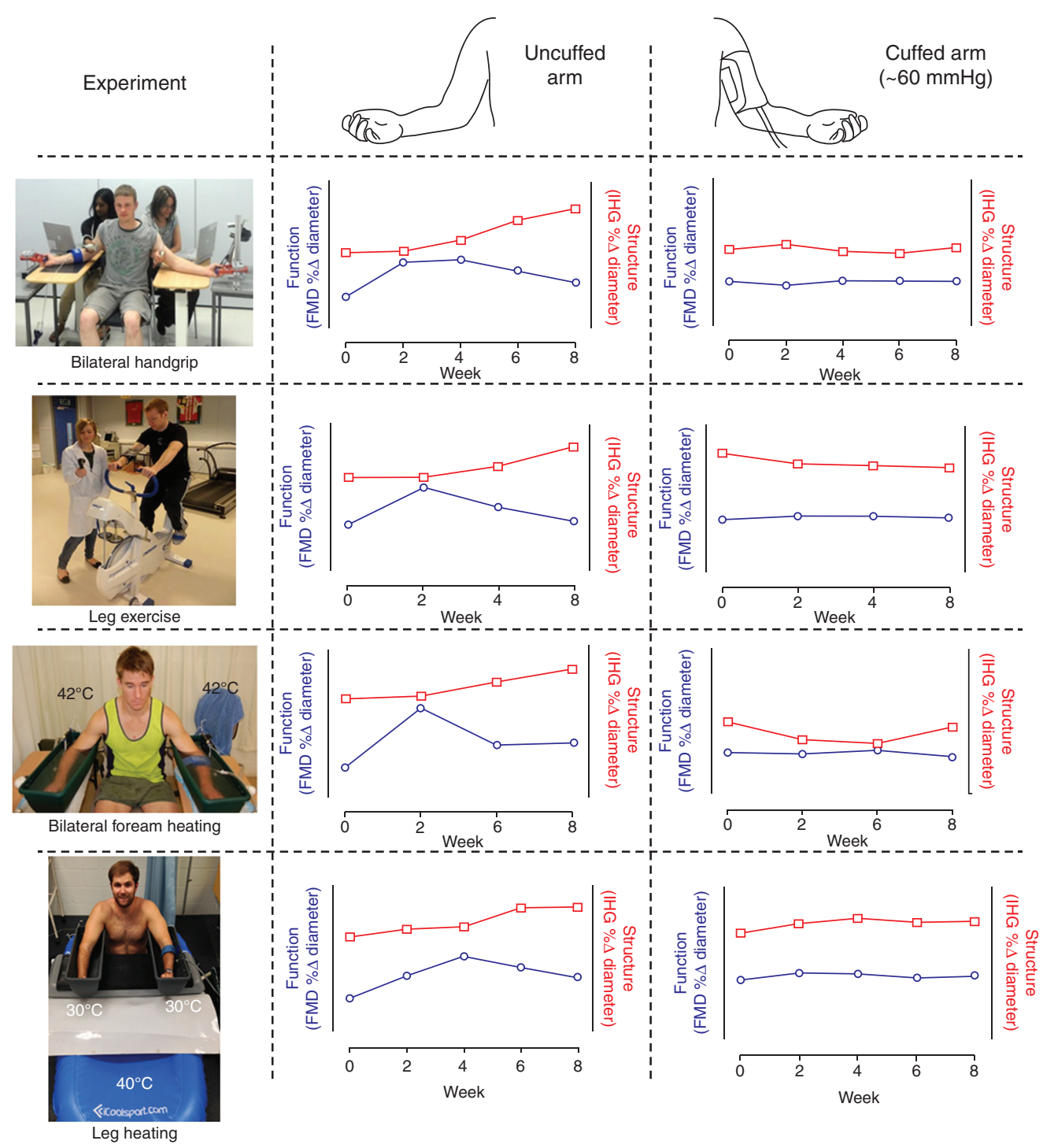

Figure 5. Impact of manipulating blood flow and shear stress during exercise bouts on the magnitude of functional and structural adaptation to exercise training in humans. These studies all adopted the use of a cuff on one limb to unilaterally decrease shear stress responses to handgrip exercise, leg exercise, forearm heating and leg heating. In all cases, an increase in shear stress was necessary for adaptations in arterial function and/or structure to be expressed (see Green et al. 2017 for further details). Note the pattern of change in function that is typically superseded by changes in structure, particularly in response to handgrip and leg exercise training. FMD, Flow-mediated dilation; IHG, isometric handgrip.

within subjects, eliminate the systemic effects of exercise on the vasculature and strongly implicate localized shear stress as an important mediator of exercise-induced vascular adaptation. Later studies using a similar unilateral upper limb cuff-clamp established that hemodynamic changes induced by leg exercise could induce adaptation in upper limb arteries and that this was also abolished in the absence of changes in blood flow and shear stress (Birk et al. 2012).

The final papers in this series tested the concept that, if exercise-induced hemodynamic 
stimuli were an important mechanism driving exercise-induced arterial adaptation, then a stimulus that emulated exercise effects on vascular hemodynamics should induce similar adaptation, even if exercise was not performed (Fig. 5). To this end, bilateral forearm heating was used, with a cuff-clamp on one limb, to induce similar increases in blood flow and shear stress to the upper limbs as those observed during exercise (Naylor et al. 2011; Carter et al. 2013). Repeated heating induced conduit artery adaptation, consistent with that observed as a consequence of exercise training, with no adaptation, observed in the cuffed limb that was not exposed to increases in blood flow or shear stress. These findings reinforce the studies described above, in that they prove a role for hemodynamic stimuli in the functional and structural changes that occur in arteries as a result of exercise training.

\section{EXERCISE TRAINING AND STRUCTURE- FUNCTION INTERACTION}

In the studies described above (Tinken et al. 2010b; Naylor et al. 2011; Birk et al. 2012; Carter et al. 2014), and some earlier work (Laughlin 1995; Tinken et al. 2008), temporal relationships between changes in arterial function and structure were assessed (Fig. 5). The rationale for assessment of the time-course of exercise training-induced change was based on the inference of Laughlin (1995), a decade earlier, based on integrative analysis of animal studies performed in his laboratory. He proposed that functional adaptation in response to exercise might precede structural remodeling. This proposal has some mechanistic foundation, in that chronic changes in the production of endothelium-derived substances such as NO are known to play a role in arterial remodeling (Tronc et al. 1996; Rudic et al. 1998; Tuttle et al. 2001). Hence, initial up-regulation of arterial function as a result of exercise bouts, including the repeated episodic release of local paracrine compounds, might ultimately lead to up-regulation of NO-synthase bioavailability (Cai and Harrison 2000), which modifies underlying wall structure and induces outward remodeling. In this way, the synergistic interaction between function and structure normalizes local shear stress as observed in animal preparations (Rodbard 1975; Hutcheson and Griffith 1992).

To test this notion in humans, studies were designed in which indices of arterial function (FMD) and structure (peak reactive hyperemic diameter) were assessed every 2 weeks across the 8 -week time-course of an exercise training program (Fig. 5). Tinken et al. reported, in both brachial and popliteal arteries, that a distinct time-course of adaptation occurred, with initial enhancements in function superseded by structural remodeling (Thijssen et al. 2008). Subsequent studies (Tinken et al. 2008; Naylor et al. 2011; Birk et al. 2012; Hunt et al. 2013; Carter et al. 2014) have largely endorsed the notion that changes in the regulation of arterial function occur rapidly, within perhaps three or four sessions of exercise (Wang et al. 1993; McAllister and Laughlin 1997). The consequent up-regulation of functional pathways can contribute to arterial remodeling, which, once expressed, allows function to return toward baseline levels. This interrelationship may act to homeostatically regulate wall shear stress, as suggested in some early experiments (Rodbard 1975; Langille and O'Donnell 1986; Tronc et al. 1996).

\section{SOME THINGS WE DO NOT KNOW ABOUT EXERCISE TRAINING AND ARTERIAL ADAPTATION}

The sections above indicate that there is compelling evidence that exercise training modifies arterial function and structure in humans. Whereas some of the exercise impact may be ascribed to changes in traditional CV risk factors, it is now clear that repeated hemodynamic stimulation as a result of episodic bouts of exercise, and consequent changes in blood pressure, tangential wall stress, and shear stress contribute to arterial adaptation (Green et al. 2017). However, there are a number of important physiological questions that remain unanswered requiring future animal and human studies of the impacts of exercise training.

Many studies that have focused on vascular functional adaptation have interrogated the $\mathrm{NO}$ 
dilator pathway. Less is known regarding exercise training-induced changes in prostaglandinmediated vascular function (Hellsten et al. 2012), which is surprising given that its discovery predated that of $\mathrm{NO}$ and there are blockers available. Likewise, studies on endothelin and angiotensin-mediated vasoconstriction and exercise training are scant and the impacts of training are not particularly well described (Maeda et al. 2001; Adams et al. 2005; Thijssen et al. 2007; Van Guilder et al. 2007; Nyberg et al. 2014). Also, recent evidence relating to the impacts of ischemic preconditioning raise the intriguing prospect that biologically active agents derived from working skeletal muscle may have effects on the remote vascular territories (Thijssen et al.2016).

The impact of exercise training on sympathetic regulation of vascular function has not been definitively established. On the one hand, it is clear that exercise alters autonomic balance in favor of parasympathetic, over sympathetic, function (Pagkalos et al. 2008; Mueller 2010; Munk et al. 2010), perhaps suggesting that decreased vasoconstrictor tone may contribute to training-mediated changes in vascular regulation. On the other hand, some evidence suggests that training may increase resting sympathetic vasoconstrictor tone (Alvarez et al. 2005; Sugawara et al. 2007), whereas other evidence suggests that resting and exercise control of sympathetic nerve traffic differs after training (Ray 1999). It is tempting to speculate that the increases in arterial vasodilator function and capacity induced by training may be compensated, at rest, by increased sympathetic tone, such that resting blood flow or arterial diameter remain unaltered. This proposal requires further investigation and the situation may be different in healthy subjects and those with elevated sympathetic drive a priori (Roveda et al. 2003; Carter and Ray 2015). It is also now clear that important differences in autonomic function may result from differences in receptor density and function that exist between men and women of different ages (Green et al. 2015; Joyner et al. 2015).

The impact of oxidative stress and inflammation on exercise training-induced vascular regulation is also unclear. While interactions between $\mathrm{NO}$ and oxidative and inflammatory species (e.g., superoxide anion) have been understood for many years (Harrison et al. 2006), the fact that exercise may induce acute increases in these species has not been reconciled with the beneficial impacts of exercise on endothelial function. It is also apparent that some specific forms of shear stress and pressure can have proatherosclerotic impacts, at least acutely and in vitro (Harrison et al. 2006). Certainly, some well-performed studies indicate that exercise at higher intensities produces less NO-mediated functional adaptation than exercise performed at moderate levels (Goto et al. 2003), but other evidence suggests higher intensity exercise may produce favorable benefits (Ramos et al. 2015). Not enough is known about the specific balance between beneficial and detrimental impacts of oxidative and inflammatory stress following exercise training.

The nature of the interaction between arterial endothelial function and biophysical characteristics of arteries, such as arterial stiffness and pulse wave velocity (PWV), is also poorly characterized. Like FMD (Inaba et al. 2010; Green et al. 2011; Ras et al. 2013), PWV is a strong prognostic index (Ben-Shlomo et al. 2014), but the relative impact of different types of training in different regions of the vasculature (e.g., central vs. peripheral PWV) and the relationship between these measures and the functional and structural adaptation of arteries described above require further elucidation (Ashor et al. 2014).

\section{SUMMARY}

Exercise training improves vascular function, including the production and bioavailability of endothelium-derived substances such as nitric oxide, which are antiatherogenic. There is also convincing evidence for effects on arterial structure, including outward remodeling that increases arterial caliber and modifies wall-tolumen ratios. These impacts are mediated in large part by the direct effects of exercise on the vessel wall by virtue of repeated hemodynamic stimulation that occurs during each bout of exercise. Combined with the beneficial 
effects of exercise on traditional CV risk factors, these direct hemodynamic impacts of exercise on the vasculature play an important role in the prevention of CV diseases in humans.

\section{ACKNOWLEDGMENTS}

D.J.G. is supported by a National Health and Medical Research Council (NHMRC) Principal Research Fellowship (APP1080914).

\section{REFERENCES}

Adams V, Linke A, Krankel N, Erbs S, Gielen S, MobiusWinkler S, Gummert JF, Mohr FW, Schuler G, Hambrecht R. 2005. Impact of regular physical activity on the $\mathrm{NAD}(\mathrm{P}) \mathrm{H}$ oxidase and angiotensin receptor system in patients with coronary artery disease. Circulation 111: 555-562.

Alvarez GE, Halliwill JR, Ballard TP, Beske SD, Davy KP. 2005. Sympathetic neural regulation in endurancetrained humans: Fitness vs. fatness. J Appl Physiol 98: 498-502.

Andersen P, Henriksson J. 1977. Capillary supply of the quadriceps femoris muscle of man: Adaptive response to exercise. J Physiol (Lond) 270: 677-690.

Anderson EA, Mark AL. 1989. Flow-mediated and reflex changes in large peripheral artery tone in humans. Circulation 79: 93-100.

Anderson L, Oldridge N, Thompson DR, Zwisler AD, Rees K, Martin N, Taylor RS. 2016. Exercise-based cardiac rehabilitation for coronary heart disease: Cochrane systematic review and meta-analysis. JACC 67: 1-12.

Ashor AW, Lara J, Siervo M, Celis-Morales C, Mathers JC. 2014. Effects of exercise modalities on arterial stiffness and wave reflection: A systematic review and meta-analysis of randomized controlled trials. PLoS ONE 9: e110034.

Ben-Shlomo Y, Spears M, Boustred C, May M, Anderson SG, Benjamin EJ, Boutouyrie P, Cameron J, Chen $\mathrm{CH}$, Cruickshank JK, et al. 2014. Aortic pulse wave velocity improves cardiovascular event prediction: An individual participant meta-analysis of prospective observational data from 17,635 subjects. JACC 63: 636-646.

Birk GK, Dawson EA, Atkinson C, Haynes A, Cable NT, Thijssen DH, Green DJ. 2012. Brachial artery adaptation to lower limb exercise training: Role of shear stress. J Appl Physiol 112: 1653-1658.

Booth FW, Chakravarthy MV, Spangenburg EE. 2002. Exercise and gene expression: physiological regulation of the human genome through physical activity. J Physiol 543: 399-411.

Brown MD. 2003. Exercise and coronary vascular remodelling in the healthy heart. Exp Physiol 88: 645-658.

Cai H, Harrison D. 2000. Endothelial dysfunction in cardiovascular diseases: The role of oxidant stress. Circ Res 87: $840-844$.
Carter JR, Ray CA. 2015. Sympathetic neural adaptations to exercise training in humans. Auton Neurosci 188: 36-43.

Carter HH, Dawson EA, Birk GK, Spence AL, Naylor LH, Cable NT, Thijssen DHJ, Green DJ. 2013. Effect of shear rate manipulation on conduit artery dilation in humans. Hypertension 61: 143-150.

Carter HH, Spence AL, Atkinson CL, Pugh CJA, Naylor LH Green DJ. 2014. Repeated core temperature elevation induces conduit artery adaptation in humans. Eur J Appl Physiol 114: 859-865.

Carter HH, Gong P, Kirk RW, Es'haghian S, Atkinson CL, Sampson DD, Green DJ, McLaughlin RA. 2016. Optical coherence tomography in the assessment of acute changes in cutaneous vascular function in humans. $J$ Appl Physiol 121: 965-972.

Celermajer DS, Sorensen KE, Gooch VM, Spiegelhalter DJ, Miller OI, Sullivan ID, Lloyd JK, Deanfield JE. 1992. Non-invasive detection of endothelial dysfunction in children and adults at risk of atherosclerosis. Lancet 340: $1111-1115$.

Currens JH, White PD. 1961. Half century of running: Clinical, physiological and autopsy findings in the case of Clarence De Mar, "Mr. Marathoner." N Engl J Med 265: 988-993.

Dinenno FA, Tanaka H, Monahan KD, Clevenger CM, Eskurza I, DeSouza CA, Seals DR. 2001. Regular endurance exercise induces expansive arterial remodeling in the trained limbs of healthy men. J Physiol 534: 287-295.

Folkow B. 1978. Cardiovascular structural adaptation: Its role in the initiation and maintenance of primary hypertension. Clin Sci Mol Med 55: 3s-22s.

Folkow B, Grimby G, Thulesius O. 1958. Adaptive structural changes in the vascular walls in hypertension and their relation to the control of peripheral resistance. Acta Physiol Scand 44: 255.

Furchgott RF, Zawadzki JV. 1980. The obligatory role of endothelial cells in the relaxation of arterial smooth muscle by acetylcholine. Nature 288: 373-376.

Goto C, Higashi Y, Kimura M, Noma K, Hara K, Nakagawa K, Kawamura M, Chayama K, Yoshizumi M, Nara I. 2003. Effect of different intensities of exercise on endotheliumdependent vasodilation in humans: Role of endothelium-dependent nitric oxide and oxidative stress. Circulation 108: $530-535$.

Green DJ, Cable NT, Fox C, Rankin JM, Taylor RR. 1994. Modification of forearm resistance vessels by exercise training in young men. J Appl Physiol 77: 1829-1833.

Green DJ, Fowler DT, O'Driscoll JG, Blanksby BA, Taylor RR. 1996. Endothelium-derived nitric oxide activity in forearm vessels of tennis players. J Appl Physiol 81: 943-948.

Green DJ, O’Driscoll JG, Blanksby BA, Taylor RR. 1997. Effect of casting on forearm resistance vessels in young men. Med Sci Sports Exerc 29: 1325-1331.

Green D, Cheetham C, Mavaddat L, Watts K, Best M, Taylor R, O'Driscoll G. 2002a. Effect of lower limb exercise on forearm vascular function: Contribution of nitric oxide. Am J Physiol Heart Circ Physiol 283: H899-H907.

Green D, Cheetham C, Reed C, Dembo L, O'Driscoll G. 2002b. Assessment of brachial artery blood flow across 
the cardiac cycle: Retrograde flows during cycle ergometry. J Appl Physiol 93: 361-368.

Green DJ, Maiorana AJ, O’Driscoll G, Taylor R. 2004. Topical review: Effects of exercise training on vascular endothelial nitric oxide function in humans. J Physiol (Lond) 561: $1-25$.

Green DJ, Bilsborough W, Naylor LH, Reed C, Wright J, O'Driscoll G, Walsh JH. 2005. Comparison of forearm blood flow responses to incremental handgrip and cycle ergometer exercise: Relative contribution of nitric oxide. J Physiol (Lond) 562: 617-628.

Green DJ, O’Driscoll G, Joyner MJ, Cable NT. 2008. Exercise and cardiovascular risk reduction: time to update the rationale for exercise? J Appl Physiol 105: 766-768.

Green DJ, Jones H, Thijssen D, Cable NT, Atkinson G. 2011. Flow-mediated dilation and cardiovascular event prediction: Does nitric oxide matter? Hypertension 57: 363-369.

Green DJ, Hopkins ND, Jones H, Thijssen DHJ, Eijsvogels TMH, Yeap BB. 2015. Sex differences in artery function and health in humans: Impacts of exercise. Exper Physiol 101: $230-242$.

Green DJ, Hopman MTE, Padilla J, Laughlin MH, Thijssen DHJ. 2017. Vascular adaptation to exercise in humans: The role of hemodynamic stimuli. Physiol Rev 97: 495528.

Hambrecht R, Wolf A, Gielen S, Linke A, Hofer J, Erbs S, Schoene N, Schuler G. 2000. Effect of exercise on coronary endothelial function in patients with coronary artery disease. NEJM 342: 454-460.

Hambrecht R, Adams V, Erbs S, Linke A, Krankel N, Shu Y, Baither Y, Gielen S, Thiele H, Gummert JF, et al. 2003. Regular physical activity improves endothelial function in patients with coronary artery disease by increasing phosphorylation of endothelial nitric oxide synthase. Circulation 107: 3152-3158.

Hambrecht R, Walther C, Mobius-Winkler S, Gielen S, Linke A, Conradi K, Erbs S, Kluge R, Kendziorra K, Sabri O, et al. 2004. Percutaneous coronary angioplasty compared with exercise training in patients with stable coronary artery disease: A randomized trial. Circulation 109: 1371-1378.

Harrison DG, Widder J, Grumbach I, Chen W, Weber M, Searles C. 2006. Endothelial mechanotransduction, nitric oxide and vascular inflammation. J Intern Med 259: 351363.

Hellsten Y, Jensen L, Thaning P, Nyberg M, Mortensen S. 2012. Impaired formation of vasodilators in peripheral tissue in essential hypertension is normalized by exercise training: Role of adenosine and prostacyclin. J Hypertens 30: $2007-2014$.

Hunt JE, Galea D, Tufft G, Bunce D, Ferguson RA. 2013. Time course of regional vascular adaptations to low load resistance training with blood flow restriction. J Appl Physiol 115: 403-411.

Huonker M, Schmid A, Schmid-Truckass A, Grathwohl D, Keul J. 2003. Size and blood flow of central and peripheral arteries in highly trained able-bodied and disabled athletes. J Appl Physiol 95: 685-691.

Hutcheson IR, Griffith TM. 1992. Endothelium-derived relaxing factor release is modulated both by the frequency and amplitude of pulsatile flow. In The biology of nitric oxide: Physiological and clinical aspects (ed. Moncada S, Marletta MA, Hibbs JBJ, Higgs EA). Portland, London.
Inaba Y, Chen JA, Bergmann SR. 2010. Prediction of future cardiovascular outcomes by flow-mediated vasodilatation of the brachial artery: A meta-analysis. Int J Cardiovasc Imag 26: 631-640.

Jasperse JL, Laughlin MH. 2006. Endothelial function and exercise training: Evidence from studies using animal models. Med Sci Sports Exerc 38: 445-454.

Joyner MJ, Dietz NM, Shephard JT. 2001. From Belfast to Mayo and beyond: The use and future of plethysmography to study blood flow in humans limbs. J Appl Physiol 91: $2431-2441$.

Joyner MJ, Green DJ. 2009. Exercise protects the cardiovascular system: Effects beyond traditional risk factors. $J$ Physiol 587: 5551-5558.

Joyner MJ, Barnes JN, Hart EC, Wallin BG, Charkoudian N. 2015. Neural control of the circulation: How sex and age differences interact in humans. Compr Physiol 5: 193215.

Langille BL, O'Donnell F. 1986. Reductions in arterial diameter produced by chronic decreases in blood flow are endothelium-dependent. Science 231: 405-407.

Laughlin MH. 1995. Endothelium-mediated control of coronary vascular tone after chronic exercise training. Med Sci Sports Exerc 27: 1135-1144.

Maeda S, Miyauchi T, Kakiyama T, Sugawara J, Iemitsu M, Irukayama-Tomobe Y, Murakami H, Kumagai Y, Kuno S, Matsuda M. 2001. Effects of exercise training of 8 weeks and detraining on plasma levels of endothelium-derived factors, endothelin-1 and nitric oxide, in healthy young humans. Life Sci 69: 1005-1016.

Maiorana A, O'Driscoll G, Dembo L, Cheetham C, Goodman C, Taylor R, Green DJ. 2000. Effect of aerobic and resistance exercise training on vascular function in heart failure. Am J Physiol 279: H1999-H2005.

Maiorana A, O'Driscoll G, Cheetham C, Dembo L, Stanton K, Goodman C, Taylor RR, Green DJ. 2001. The effect of combined aerobic and resistance exercise training on vascular function in type 2 diabetes. J Am Coll Cardiol 38: 860-866.

Maiorana AJ, Naylor LH, Exterkate A, Swart A, Thijssen DHJ, Lam K, O'Driscoll G, Green DJ. 2011. The impact of exercise training on conduit artery wall thickness and remodelling in chronic heart failure patients. Hypertension 57: 56-62.

Mann GV, Shaffer RD, Anderson RS. 1964. Cardiovascular disease in the Masai. Atheroscler Res 4: 289-312.

Manson JE, Hu FB, Rich-Edwards JW, Colditz GA, Stampfer MJ, Willett WC, Speizer FE, Hennekens CH. 1999. A prospective study of walking as compared with vigorous exercise in the prevention of coronary heart disease in women. $N$ Engl J Med 341: 650-658.

McAllister RM, Laughlin MH. 1997. Short-term exercise training alters responses of porcine femoral and brachial arteries. J Appl Physiol 82: 1438-1444.

Moncada S, Gryglewski R, Bunting S, Vane JR. 1976. An enzyme isolated from arteries transforms prostaglandin endoperoxides to an unstable substance that inhibits platelet aggregation. Nature (Lond) 263: 663-665.

Mora S, Cook N, Buring JE, Ridker PM, Lee IM. 2007. Physical activity and reduced risk of cardiovascular 
D.J. Green and K.J. Smith

events: Potential mediating mechanisms. Circulation 116: 2110-2118.

Mueller PJ. 2010. Physical (in)activity-dependent alterations at the rostral ventrolateral medulla: Influence on sympathetic nervous system regulation. Am J Physiol Regul Integr Comp Physiol 298: R1468-R1474.

Munk PS, Butt N, Larsen AI. 2010. High-intensity interval exercise training improves heart rate variability in patients following percutaneous coronary intervention for angina pectoris. Int J Cardiol 145: 312-314.

Naci H, Ioannidis JP. 2013. Comparative effectiveness of exercise and drug interventions on mortality outcomes: Metaepidemiological study. BMJ 347: f5577.

Naylor LH, Weisbrod CJ, O’Driscoll G, Green DJ. 2005. Measuring peripheral resistance and conduit arterial structure in humans using Doppler ultrasound. J Appl Physiol 98: 2311-2315.

Naylor LH, FitzSimons MG, H. C, Cable NT, Thijssen DHJ, Green DJ. 2011. Repeated increases in blood flow, independent of exercise, enhance conduit artery vasodilator function in humans. Am J Physiol 300: 664-669.

Nyberg M, Seidelin K, Andersen TR, Overby NN, Hellsten Y Bangsbo J. 2014. Biomarkers of vascular function in premenopausal and recent postmenopausal women of similar age: Effect of exercise training. Am J Physiol Regul Integr Comp Physiol 306: R510-R517.

Paffenbarger RS Jr, Hyde RT, Wing AL, Hsieh CC. 1986. Physical activity, all-cause mortality, and longevity of college alumni. N Engl J Med 314: 605-613.

Pagkalos M, Koutlianos N, Kouidi E, Pagkalos E, Mandroukas K, Deligiannis A. 2008. Heart rate variability modifications following exercise training in type 2 diabetic patients with definite cardiac autonomic neuropathy. Br J Sports Med 42: 47-54.

Pohl U, Holtz J, Busse R, Bassenge E. 1986. Crucial role of endothelium in the vasodilator response to increased flow in vivo. Hypertension 8: 37-44.

Ramos JS, Dalleck LC, Tjonna AE, Beetham KS, Coombes JS. 2015. The impact of high-intensity interval training versus moderate-intensity continuous training on vascular function: A systematic review and meta-analysis. Sports Med 45: 679-692.

Ras RT, Streppel MT, Draijer R, Zock PL. 2013. Flow-mediated dilation and cardiovascular risk prediction: A systematic review with meta-analysis. Int J Cardiol 168: 344-351.

Ray CA. 1999. Sympathetic adaptations to one-legged training. J Appl Physiol 86: 1583-1587.

Rodbard S. 1975. Vascular caliber. Cardiology 60: 4-49.

Roveda F, Middlekauff HR, Rondon MU, Reis SF, Souza M, Nastari L, Barretto AC, Krieger EM, Negrao CE. 2003. The effects of exercise training on sympathetic neural activation in advanced heart failure: A randomized controlled trial. J Am Coll Cardiol 42: 854-860.

Rowley NJ, Dawson EA, Birk GK, Cable NT, George K, Whyte G, Thijssen DH, Green DJ. 2011. Exercise and arterial adaptation in humans: Uncoupling localized and systemic effects. J Appl Physiol 110: 1190-1195.

Rowley NJ, Dawson EA, Hopman MT, George K, Whyte GP Thijssen DH, Green DJ. 2012. Conduit diameter and wall remodelling in elite athletes and spinal cord injury. Med Sci Sports Exerc 44: 844-849.

Rubanyi GM, Romero JC, Vanhoutte PM. 1986. Flow-induced release of endothelium-derived relaxing factor. $\mathrm{Am}$ J Physiol 250: H1145-H1149.

Rudic R, Sheseley E, Maeda N, Smithies O, Segal S, Sessa W. 1998. Direct evidence for the importance of endothelium-derived nitric oxide in vascular remodeling. J Clin Invest 101: 731-736.

Segal SS. 1992. Communication among endothelial and smooth muscle cells coordinates blood flow control during exercise. News Physiol Sci 7: 152-156.

Silber D, McLaughlin D, Sinoway L. 1991. Leg exercise increases peak forearm blood flow. J Appl Physiol 71: 1568-1573.

Sinoway LI, Musch TI, Minotti JR, Zelis R. 1986. Enhanced maximal metabolic vasodilatation in the dominant forearms of tennis players. J Appl Physiol 61: 673-678.

Sinoway LI, Shenberger J, Wilson J, McLaughlin D, Musch TI, Zelis R. 1987. A 30-day forearm work protocol increases maximal forearm blood flow. J Appl Physiol 62: $1063-1067$.

Sinoway LI, Hendrickson C, Davidson WRJ, Prophet S, Zelis R. 1989. Characteristics of flow-mediated brachial artery vasodilation in human subjects. Circ Res 64: 32-42.

Snell PG, Martin WH, Buckey JC, Bloomqvist CG. 1987. Maximal vascular leg conductance in trained and untrained men. J Appl Physiol 62: 606-610.

Spence AL, Carter HH, Naylor LH, Green DJ. 2013. A prospective randomized longitudinal study involving 6 months of endurance or resistance exercise. Conduit artery adaptation in humans. J Physiol (Lond) 591: $1265-1275$.

Sugawara J, Komine H, Hayashi K, Yoshizawa M, Otsuki T, Shimojo N, Miyauchi T, Yokoi T, Maeda S, Tanaka H. 2007. Systemic $\alpha$-adrenergic and nitric oxide inhibition on basal limb blood flow: Effects of endurance training in middle-aged and older adults. Am J Physiol 293: H1466-H1472.

Thijssen DH, Ellenkamp R, Kooijman M, Pickkers P, Rongen GA, Hopman MT, Smits P. 2007. A causal role for endothelin-1 in the vascular adaptation to skeletal muscle deconditioning in spinal cord injury. Arterioscler Thromb Vasc Biol 27: 325-331.

Thijssen DHJ, van Bemmel M, Bullens L, Dawson EA, Hopkins ND, Tinken TM, Black MA, Hopman MTE, Cable NT, Green DJ. 2008. The impact of baseline diameter on flow mediated dilation (FMD) differs in young and older humans. Am J Physiol 295: H1594-H1598.

Thijssen DHJ, Maiorana AJ, O’Driscoll G, Cable NT, Hopman MTE, Green DJ. 2010. Impact of inactivity and exercise on the vasculature in humans. Eur J Appl Physiol 108: $845-875$.

Thijssen DHJ, Black MA, Pyke K, Padilla J, Atkinson GA, Harris RA, Parker B, Widlansky ME, Tschakovsky ME, Green DJ. 2011a. Assessment of flow mediated dilation (FMD) in humans: A methodological and physiological guideline. Am J Physiol 300: 2-12.

Thijssen DHJ, Scholten RR, van den Monckhof ICL, Benda N, Green DJ, Hopman MTE. 2011b. Acute change in 
Effects of Exercise on Vascular Function, Structure, and Health

vascular tone alters intima-media thickness. Hypertension 58: $240-246$.

Thijssen DHJ, Cable NT, Green DJ. 2012a. Impact of exercise training on arterial wall thickness in humans. Clin Sci 122: $311-322$

Thijssen DHJ, De Groot PCE, van den Bogerd A, Veltmeijer M, Cable NT, Green DJ, Hopman MTE. 2012b. Time course of arterial remodelling in diameter and wall thickness above and below the lesion after a spinal cord injury. Eur J Appl Physiol 112: 4103-4109.

Thijssen DHJ, Maxwell J, Green DJ, Cable NT, Jones H. 2016. Repeated ischemic preconditioning: A novel therapeutic intervention and potential underlying mechanisms. Exper Physiol 101: 677-692.

Thompson PD, Buchner D, Pina IL, Balady GJ, Williams MA, Marcus BH, Berra K, Blair SN, Costa F, Franklin B, et al. 2003. Exercise and physical activity in the prevention and treatment of atherosclerotic cardiovascular disease. A statement from the Council on Clinical Cardiology (Subcommittee on Exercise, Rehabilitation, and Prevention) and the Council on Nutrition, Physical Activity, and Metabolism (Subcommittee on Physical Activity). Circulation 107: 3109-3116.

Tinken TM, Thijssen DHJ, Black MA, Cable NT, Green DJ. 2008. Time course of change in vasodilator function and capacity in response to exercise training in humans. J Physiol (Lond) 586: 5003-5012.
Tinken TM, Thijssen DH, Hopkins N, Dawson EA, Cable NT, Green DJ. 2010a. Shear stress mediates endothelial adaptations to exercise training in humans. Hypertension 55: 312-318.

Tinken TM, Thijssen DHJ, Hopkins ND, Dawson EA, Cable NT, Green DJ. 2010b. Shear stress mediates vascular adaptations to exercise training in humans. Hypertension 55: 312-318.

Tronc F, Wassef M, Esposito B, Henrion D, Glagov S, Tedgui A. 1996. Role of NO in flow-induced remodeling of the rabbit common carotid artery. Arterioscler Thromb Vasc Biol 16: 1256-1262.

Tuttle JL, Nachreiner RD, Bhuller AS, Condict KW, Connors BA, Herring BP, Dalsing MC, Unthank JL. 2001. Shear level influences resistance artery remodeling: Wall dimensions, cell density, and eNOS expression. Am J Physiol Heart Circ Physiol 281: H1380-H1389.

Van Guilder GP, Westby CM, Greiner JJ, Stauffer BL, DeSouza CA. 2007. Endothelin-1 vasoconstrictor tone increases with age in healthy men but can be reduced by regular aerobic exercise. Hypertension 50: 403-409.

Wang J, Wolin MS, Hintze TH. 1993. Chronic exercise enhances endothelium-mediated dilation of epicardial coronary artery in conscious dogs. Circ Res 73: 829-838.

Whitney RJ. 1953. The measurement of volume changes in human limbs. J Physiol 121: 1-27. 


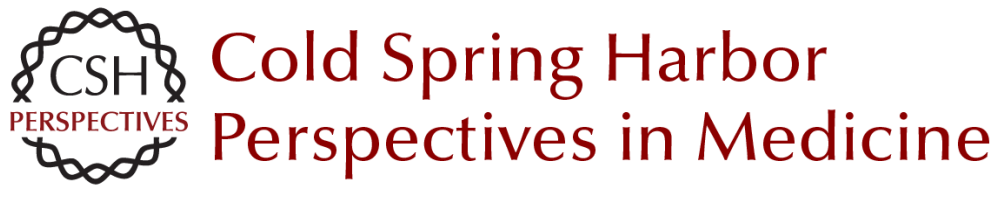

\section{Effects of Exercise on Vascular Function, Structure, and Health in Humans}

Daniel J. Green and Kurt J. Smith

Cold Spring Harb Perspect Med 2018; doi: 10.1101/cshperspect.a029819 originally published online April 21, 2017

\section{Subject Collection The Biology of Exercise}

\section{Exosomes as Mediators of the Systemic \\ Adaptations to Endurance Exercise Adeel Safdar and Mark A. Tarnopolsky}

Molecular Basis of Exercise-Induced Skeletal Muscle Mitochondrial Biogenesis: Historical Advances, Current Knowledge, and Future Challenges Christopher G.R. Perry and John A. Hawley

Exercise Metabolism: Fuels for the Fire Mark Hargreaves and Lawrence L. Spriet

Health Benefits of Exercise Gregory N. Ruegsegger and Frank W. Booth

Molecular Regulation of Exercise-Induced Muscle Fiber Hypertrophy

Marcas M. Bamman, Brandon M. Roberts and Gregory R. Adams

Physiological Redundancy and the Integrative Responses to Exercise Michael J. Joyner and Jerome A. Dempsey

On the Run for Hippocampal Plasticity C'iana Cooper, Hyo Youl Moon and Henriette van Praag

Molecular Basis for Exercise-Induced Fatigue: The Importance of Strictly Controlled Cellular $\mathrm{Ca}$ 2+ Handling Arthur J. Cheng, Nicolas Place and Håkan Westerblad
Effects of Exercise and Aging on Skeletal Muscle Giovanna Distefano and Bret $H$. Goodpaster

Muscle-Adipose Tissue Cross Talk Kristin I. Stanford and Laurie J. Goodyear

Performance Fatigability: Mechanisms and Task Specificity Sandra K. Hunter

Adaptations to Endurance and Strength Training David C. Hughes, Stian Ellefsen and Keith Baar

The Bioenergetics of Exercise P. Darrell Neufer

Effects of Exercise on Vascular Function, Structure, and Health in Humans Daniel J. Green and Kurt J. Smith

Control of Muscle Metabolism by the Mediator Complex Leonela Amoasii, Eric N. Olson and Rhonda Bassel-Duby

Theoretical and Biological Evaluation of the Link between Low Exercise Capacity and Disease Risk Lauren Gerard Koch and Steven L. Britton

For additional articles in this collection, see http://perspectivesinmedicine.cshlp.org/cgi/collection/ 